\title{
WHEN HOLLYWOOD INSPIRES MEDICINE: NEW CONCEPTS IN THE DESIGN AND ARCHITECTURE OF MEDICAL SIMULATION FACILITIES TO SUPPORT INTER-PROFESSIONAL HEALTHCARE EDUCATION AND TRAINING
}

\author{
Allan Hamilton \\ Marissa Lovett \\ David Biffar \\ Arizona Simulation Technology Education Center \\ University of Arizona \\ 1501 N. Campbell Avenue \\ Tucson, AZ, USA \\ \{allan,dbiffar\}@surgery.arizona.edu \\ Lovett1@email.arizona.edu \\ Jerzy Rozenblit \\ Department of Electrical \& Computer Engineering \\ University of Arizona \\ 1230 E. Speedway Blvd. Suite 506 \\ Tucson, AZ, USA \\ jr@ece.arizona.edu
}

\author{
Jonathan Kanda
}

\author{
Co Architects, Inc. \\ 5055 Wilshire Boulevard, $9^{\text {th }}$ Floor \\ Los Angeles, California 90036 \\ jkanda@coarchitects.com
}

Ronald Weinstein

Arizona Telemedicine Program

University of Arizona Health Sciences

P.O. Box 235105

Tucson, AZ, USA

rweinstein@telemedicine.arizona.edu

\begin{abstract}
ABSTACT
The changing landscape of healthcare education, delivery, and technology is placing new demands for significant inter-disciplinary and inter-professional training in medical simulation. New architectural concepts and building designs must ensure that large-scale healthcare simulation facilities offer customized training opportunities for nursing, medicine, public health, and pharmacy while allowing for maximal flexibility and adaptation across nearly fifty different user groups and stake holders. A novel concept of a larger, configurable "stage" design, more akin to a Hollywood production studio, with in-patient and outpatient suites seen as temporary or "standing" sets was created. The stage, called a "Sim Deck," can be easily dismantled while providing ample square footage for mass casualty scenarios. The facility required significant technological support to provide remote simulation training via existing and future telemedical technologies as well as remaining nimble enough to incorporate technologies in augmented and virtual reality, artificial intelligence, and large-scale learner management systems.
\end{abstract}

Keywords: architecture, healthcare, informational technologies, inter-professional, medical simulation

\section{INTRODUCTION}

Nearly two decades ago, the Institute of Medicine (IOM) published To Err Is Human: Building A Safer Health System (Institute of Medicine, 2000). In it, they identified problems with inter-disciplinary communication and teamwork as one of the primary contributors to preventable medical adverse events (MAEs). Across several different medical disciplines and subspecialties, studies (Risser et al. 1999, Morey 
et al. 2002, Pronovost et al 2003, Nielsen et al 2007) have demonstrated that a significant and sizeable proportion of MAEs can be eliminated by encouraging and improving educational strategies that enhance inter-professional education and processing (IPEP), teamwork, and communication skills. A 2010 survey (Passiment, Sacks, and Huang, 2011) of 90 medical school and 64 teaching hospitals carried out by the Association of American Medical Colleges demonstrated that healthcare simulation-based training (HSBT) is used by approximately $85 \%$ of the medical schools and $65 \%$ of post-graduate medical education (GME) training programs surveyed. Similarly, a 2010 survey (Hayden et al, 2014) by the National Council of State Boards of Nursing found that $87 \%$ of respondents used high- or medium-HSBT as part of the nursing educational programming. To this day, however, much of HSBT remains narrowly focused and centered by discipline and subspecialty. The facilities, staff, and instructors often remain segregated in separate buildings, administered as independent administrative entities within the same corporate and academic institutions, and, in the past, were assigned to a wide range of parochial certification agencies. Great strides have been taken by the Society for Simulation in Healthcare (SSH) to serve as a unifying and universal certifying body for HSBT facilities around the world and across specialties. Nonetheless, cross-training between disciplines and healthcare professions still remains the exception and not the rule from a practical level.

In a follow-up report to its initial 1999 assessment, the IOM published Health Professions Education: A Bridge to Quality (Greiner and Knebel, 2003). In it, the authors state: "In many training settings, the institutional norms are such that authoritarianism, boundaries of practice, and silos among professional disciplines are strictly enforced, and further reinforced by payment systems. In such settings, the value of interdisciplinary teams will likely not be grasped by students ....although the academic environment of the various health professions generally are not interdisciplinary, practice environments are increasingly so, posing a serious disconnect." The report goes on to recommend that "...the developing and funding of regional demonstration learning centers, representing partnerships between practice and education. These centers should leverage existing innovative organizations and state-of-the-art training settings focused on teaching and assessing a set of core competencies (Greiner and Knebel, 2003)."

In this vein, the Arizona Simulation Technology and Education Center (ASTEC) provides a unique perspective on the value of interdisciplinary HSBT. In part, this arises from sharing a common campus with the Colleges of Medicine (COM), Nursing (CON), Pharmacy (COP), and Public Health (COPH), and the primary teaching hospital, Banner University Medical Center (BUMC) in Tucson. This made large-scale inter-disciplinary training exercises possible under the auspices of ASTEC. These exercises engage one year's entire class of students from each of the four colleges to participate as teams in joint simulation exercises in which undergraduate students not only are assigned roles in their own discipline, but are required to role play those of other professions in the healthcare team. To date, these full-scale exercises (involving more than 250 students in a single day) have focused on areas of common and mutual interest such as cardiopulmonary resuscitation (CPR) and pandemic exercises surrounding widespread activation of first responder networks.

ASTEC serves as the common HBST facility for undergraduate and post-graduate training programs in the $\mathrm{COM}$ and $\mathrm{CON}$ and has begun to seek out areas of commonality for training. So, for example, although anesthesiologists and nurse anesthetists answer to different supervisory and regulatory agencies, the training required by both the medical and nursing schools has enormous overlap in terms of didactic materials and the need for practical skills assessment. In addition, in situ team training is carried out routinely to assess individual skills but also measure the overall proficiency of multi-disciplinary team responses to challenging clinical scenarios. Finally, many of lessons learned from our educational partners, such as the Arizona Telemedicine Program (ATP), COM-Phoenix and the Banner Health (BH) organization have helped to reinforce the need to rise to the challenge of multidisciplinary curricula and inter-professional education as an integral part of the design of our educational facility. To meet these educational needs at the University of Arizona, a novel simulation center was designed within the Health Sciences Innovation Building (HSIB). ASTEC will be operational in the HSIB simulation facility in Spring 2019. 
This paper describes how architectural and design features were combined to create a unique regional demonstration learning center for inter-professional HSBT. It outlines the educational and technological challenges in creating a such a facility as well as the physical, informational, and methodological issues a facility must be prepared to meet to ensure it remains educationally, clinically, and culturally relevant.

\section{HISTORY AND MISSIONS OF MEDICAL SIMULATION CENTERS}

Simulation traces its origins to the late 1920's when Edwin Link of Binghamton, NY began building the world's first aviation simulators. He created an aviation simulator to produce reliable and predictable changes in the gauges and instruments displayed on a mock cockpit panel. Eventually, Link refined his design to provide the user with the physical sensations of roll, pitch, and yaw in response to changes in the pilot's controls. Link trainers were mass-produced to accelerate pilot training among the Allied nations during World War II (Kelly, 1979).

Inspired by aviation simulators, medical simulation began in the 1980's with anesthesia departments developing operating room equipment that depicted variable physiological and laboratory data as a method for reducing MAEs. (Rosen 2008). Concurrently, funding became available through the Department of Defense for the development of high-fidelity mannequins for training medics for certification in the Combat Casualty Care Course, now known in the military as the Tactical Combat Casualty Care (TCCC) course. Over the last two decades, numerous medical simulation technologies have been developed commercially for the civilian sectors. From 2000-2010 the number of medical simulation centers in the United States rose from one hundred to over one thousand (Sherwin, 2014). Medical simulation grew from high-fidelity computerized mannequins (HFCM) to virtual reality (VR)-based trainers with haptic feedback, procedural trainers, immersive VR (iVR), and game- and avatar-based multiplayer games.

\section{MISSION AND USER GROUPS}

Several factors play a role in the design of a successful simulation facility (Seropian and Lavey, 2010). These include the mission of the facility, needs of various user groups, design and space requirements, flexible multi-use design, and budget and supporting revenue streams. For example, the educational needs of undergraduates in the healthcare professional schools would be a priority for the design of simulation facility but, if significant subsidization of that mission was derived from research and development funds from bio-industrial partnerships and/or government funding agencies, then the space for dedicated research and bio-innovation spaces would require greater emphasis to balance the two missions.

ASTEC's mission has grown much more complex (see Table 1) from its beginnings as a simple procedurebased educational facility in 2004. A decade and a half later, it now provides tools for missions ranging from competency assessment to more sophisticated diagnostic and technical certification and credentialing. Increasingly, in an age where training hours are more strictly curtailed, medical simulation is being seen as a way to ensure that healthcare students and post graduate trainees gain the requisite exposure to a sufficiently wide spectrum of disease presentations and severities to make up for decreased clinical availability. In addition, numerous American Council on Graduate Medical Education (ACGME)-approved residencies (GME) and fellowship training programs now have increased the amounts of required and/or recommended simulation training as part of their programming. HSBT also includes immersive individual and group lessons to supplement (and in some cases supplant) non-clinical and basic science curriculum traditionally reserved for the first two years of medical school. The facility must provide pragmatic tools for assessing inter-professional communication skills, ensuring clinical educational outreach to underserved and rural healthcare facilities, supporting in situ team training in the hospital, and participating in outcomes research and analysis to develop and assess best practices for reducing preventable MAEs. 
Table 1: Training Mission of Healthcare Simulation-Based Training (HBST).

\begin{tabular}{|c|c|c|}
\hline $\begin{array}{l}\text { Training } \\
\text { Mission/Objectives }\end{array}$ & Equipment & User groups \\
\hline $\begin{array}{l}\text { Procedural training } \\
\& \text { assessment; } \\
\text { competency } \\
\text { assessment \& } \\
\text { credentialing }\end{array}$ & $\begin{array}{l}\text { High-fidelity computerized mannequins, } \\
\text { Procedural task trainers, Standardized } \\
\text { patients, VR-based trainers }\end{array}$ & $\begin{array}{l}\text { First responders, healthcare } \\
\text { education undergraduates, } \\
\text { GME and fellowship training }\end{array}$ \\
\hline $\begin{array}{l}\text { Mandatory GME } \\
\text { training }\end{array}$ & $\begin{array}{l}\text { High-fidelity computerized, Mannequins, } \\
\text { Procedural task trainers, VR-based trainers, } \\
\text { Angiography, endovascular trainers, Surgical } \\
\text { robotic trainers }\end{array}$ & $\begin{array}{l}\text { Residents, fellows, other } \\
\text { healthcare professionals }\end{array}$ \\
\hline $\begin{array}{l}\text { Non-clinical basic } \\
\text { sciences }\end{array}$ & $\begin{array}{l}\text { High-fidelity computerized mannequins, } \\
\text { Procedural task trainers, Standardized } \\
\text { patients, VR-based trainers, Synthetic } \\
\text { cadavers, VR-based anatomy tables }\end{array}$ & $\begin{array}{l}\text { Undergraduates, non-medical } \\
\text { programs (e.g. biomedical } \\
\text { engineering, physiology) }\end{array}$ \\
\hline $\begin{array}{l}\text { Interprofessional } \\
\text { Education and } \\
\text { Processing (IPEP) }\end{array}$ & $\begin{array}{l}\text { High-fidelity computerized mannequins, } \\
\text { Procedural task trainers, Standardized } \\
\text { patients, Avatar-based multi-player games } \\
\text { Group processing games }\end{array}$ & $\begin{array}{l}\text { First responders, } \\
\text { undergraduate \& GME users; } \\
\text { in situ hospital team/unit } \\
\text { training }\end{array}$ \\
\hline Epidemiology & $\begin{array}{l}\text { VR, multi-players games, telemedicine; } \\
\text { large-team/whole class pandemic exercises }\end{array}$ & $\begin{array}{l}\text { Healthcare professionals, first } \\
\text { responders, public health, } \\
\text { government emergency } \\
\text { agencies }\end{array}$ \\
\hline $\begin{array}{l}\text { Rural, State, } \\
\text { Regional, \& } \\
\text { International } \\
\text { Outreach }\end{array}$ & $\begin{array}{l}\text { High-fidelity computerized mannequins, } \\
\text { Procedural task trainers, Standardized } \\
\text { patients, VR-based trainers, Synthetic } \\
\text { cadavers, VR-based anatomy tables, } \\
\text { telemedicine }\end{array}$ & $\begin{array}{l}\text { Undergraduates, non-medical } \\
\text { programs (e.g. biomedical } \\
\text { engineering, physiology); } \\
\text { healthcare professionals, first } \\
\text { responders, public health, } \\
\text { government emergency } \\
\text { agencies; middle \& high } \\
\text { school science programs }\end{array}$ \\
\hline $\begin{array}{l}\text { Artificial Tissue } \\
\text { Lab }\end{array}$ & $\begin{array}{l}\text { Dedicated laboratory \& manufacturing } \\
\text { facility; 3-D soft tissue printing }\end{array}$ & $\begin{array}{l}\text { Undergraduates, non-medical } \\
\text { programs (e.g. biomedical } \\
\text { engineering, physiology }\end{array}$ \\
\hline $\begin{array}{l}\text { Research \& } \\
\text { Development }\end{array}$ & Dedicated lab facility \& innovation spaces & $\begin{array}{l}\text { Bio-industrial partners; } \\
\text { military, government agencies }\end{array}$ \\
\hline
\end{tabular}

\subsection{Design Group}

To draw together ideas and stakeholders for the planning of the new facility in the proposed HSIB, multiple focus and design group meetings were conducted. Initially, the purpose was to brainstorm ideas but, later, the group functioned to narrow and focus consensus for architectural planning.

The composition of the design group (see Table 2) for a facility of the size and complexity envisioned for this facility requires a delicate balance of inclusion and effective consensus. Naturally, the larger the design group, the greater the inclusion but, often, the harder it becomes to develop consensus. In addition, several key committees and working groups would report their findings to the design group by sending designated representatives to present to the design group. 
Table 2: User Groups \& Design Team Members.

\begin{tabular}{|l|l|}
\hline User Groups-Designated Design Team Members & Function-Responsibilities \\
\hline Facilities Management & Oversight \& administration \\
\hline Architectural \& Design Consultants & Overall building design \\
\hline Health Sciences Administration & Oversight and financing \\
\hline $\begin{array}{l}\text { COM, CON, COP, COPH (representatives from } \\
\text { each Dean of the four colleges and one student } \\
\text { representative from each of the colleges) }\end{array}$ & $\begin{array}{l}\text { Curriculum for COM undergraduates, learner } \\
\text { management systems; educational and human } \\
\text { factors support }\end{array}$ \\
\hline GME & $\begin{array}{l}\text { Training needs and requirements for ACGME- } \\
\text { related program requirements and needs }\end{array}$ \\
\hline BUMC & $\begin{array}{l}\text { Hospital-related training needs both for GME as } \\
\text { well as hospital staff and team training }\end{array}$ \\
\hline $\begin{array}{l}\text { Audiovisual (AV), Biomedical Communications } \\
\text { (BioComm), Informational Technology (IT), and } \\
\text { Arizona Telemedicine Program }\end{array}$ & AV and It infrastructure \& connectivity \\
\hline $\begin{array}{l}\text { Design group from School of Theater, Film and } \\
\text { Television }\end{array}$ & Theatrical design input and advice \\
\hline UHSC \& Eller School of Business & Financial planning and projections \\
\hline
\end{tabular}

A 12-person group representing the student body in the COM reviewed simulation in the medical curriculum. There was also a group reporting directly to the Dean which kept our design group informed about GME needs and wishes. The Curriculum Committee kept the design group informed about curriculum-related changes. Reports were sought from AV/IT, BioComm, ATP, our rural outreach program, and the Development Office. The design group included senior leadership from UHSC and the University, the Asst. Vice President in charge of the project, deans from each college (or designated stand-in), members from the architectural firm, two ASTEC staff, designated student representatives, and the Assoc. Dean for Education from the COM, and officers from the Development Office.

\subsection{Design and Space Needs Assessment}

A University of Arizona survey of faculty from all four health sciences colleges was performed to query them about future simulation needs. The take-home message was that most faculty assumed there would be anywhere from $25-50 \%$ increase in their simulation needs. No single respondent felt that their use of simulation would diminish over the ensuing decade.

In addition, all four colleges were in the midst of a major overhaul of the undergraduate curricula and the deans reported an increased need for immersive learning experiences. This meant that where, in the past, simulation had focused primarily on procedurally-oriented in support of the clinical rotations, now it would have to broaden its approach to provide immersive experiences to reinforce didactic content for the preclinical years. A survey from the GME Committee indicated that mandatory GME simulation needs were rising quickly and, at our own institution, were roughly doubling every two years (Amer. Assoc. Med. Colleges, 2011).

The University also opened up a new College of Veterinary Sciences (CVS) with both large- and smallanimal tracks of study. The CVS has anticipated support from University of Arizona Health Sciences (UAHS) to ensure development of artificial tissue modules to meet the training and procedural needs of their own trainees.

\subsection{Special Requests}

Besides traditional simulation needs based on scenario-based training, procedural training, virtual reality trainers, large-scale HBST must be able to meet varied and diverse training and education missions. Often 
GME-related requirements require far more sophisticated technological support than simpler undergraduate curricular needs. Robotic, endoscopic, laparoscopic, endovascular (angiographic), and microsurgical simulation training require significant investments in infrastructure and capital equipment. This makes the ability to flexibly configure suites for specific procedural training, assessment, or diagnostic evaluation all the more important.

\subsection{Multidisciplinary Context}

One of the most pressing needs for the design of the HSIB was that it be multidisciplinary in nature and inclusive of all the simulation and training needs of the four colleges on the healthcare campus, the UAHS, as well as meet the GME and collaborative research needs of the entire university. Furthermore, it must provide adequate and compelling simulation space for outside users such as first responders.

\subsection{Through-Put Capacity}

Annual inter-professional exercises held at ASTEC required that multiple classes with multiple simulations be scheduled over the course of several days. This ensured complete participation of the entire classes from all four colleges. Such protracted scheduling made it difficult to coordinate simulation and classroom didactics in an appropriate fashion. Because of these demands, the new facility was designed to meet the throughput needs of 300 students in a single day.

\subsection{Accessibility to Public and User Groups}

The simulation area also had to be easily accessible with card-swipe access from multiple doors so that traffic could be directed from several different adjacent classrooms and debriefing rooms. At the same time, the design group also wanted to invite the public to see how healthcare providers train and practice. One of the main goals of the HSIB was to be more inclusive of the community and to also inspire a new, younger generation to take an interest in healthcare and healthcare career choices.

To this end, we began playing with the concept of looking at simulation as equivalent to theater in the round. Inspired by Shakespeare's famous Globe Theater outside London, England, we began evaluating design concepts of where the public and user groups might be able to "look in" at activities in real-time as they took place in the simulation facility.

This concept of a theater-in-the-round was difficult to design so as to ensure adequate but selective access for public viewing (see Figure 1). It also consumed enormous amounts of space that was non-productive. It became clear that we could conceive of a circular space, around which the public could flow for viewing - much like an aquarium - but this still don't utilize the space well and curved surfaces would require a great deal of expensive customized construction. This led to the adoption of square or rectangular design allowed to create galleries on the outside of the simulation spaces that would allow the public to look in through glass walls to watch training (see Figure 1). It was also recognized that the glass would need to be screened in certain cases where privacy was required.

The simulation suites were designed so that they could be redundant but also permit sufficient expansion to accommodate everything from small groups to entire classes at one time. 


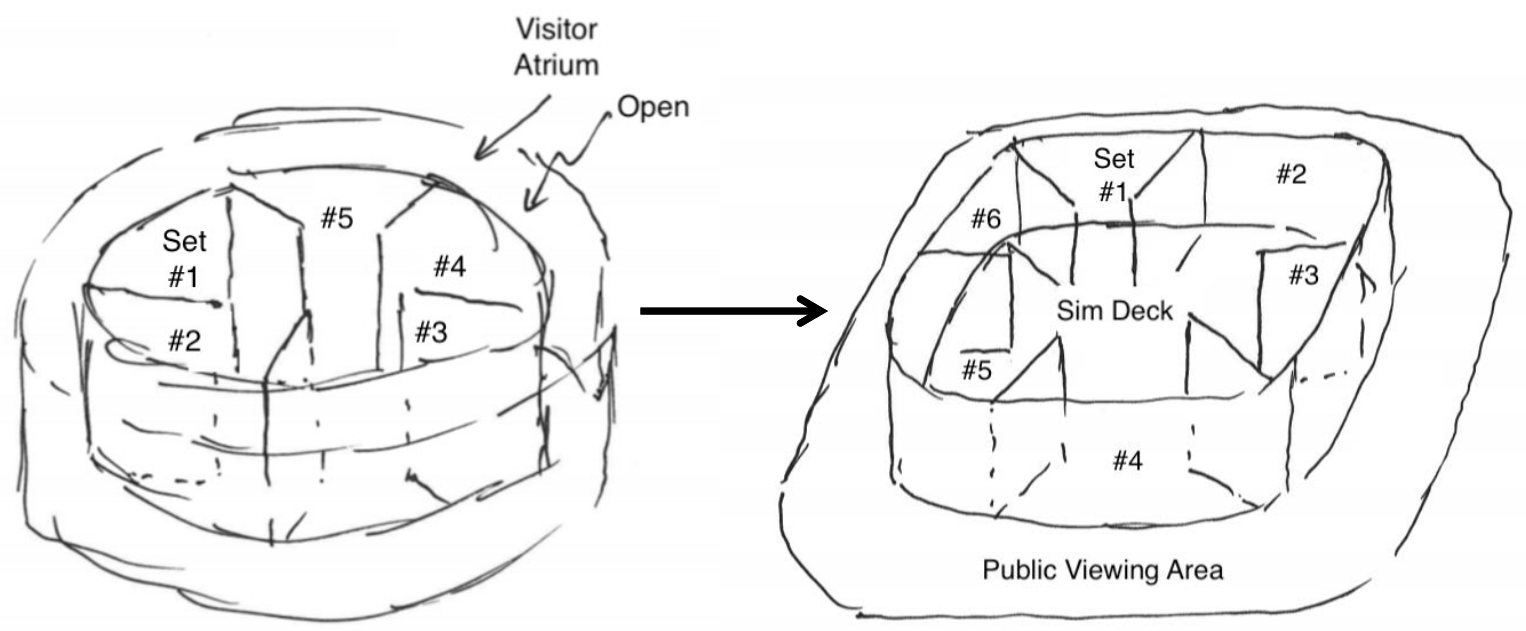

Figure 1: Senior author's first conceptual drawings of a simulation space which morphed from circular to square to take better advantage of space and building materials.

\subsection{The "Sim Deck" Concept}

In their chapter on the historic perspectives on medical and surgical simulation in the textbook Surgical Simulation, Bahsoun et al. state:

"The prefect training tool would be the one that can combine simulation, immersion, and interaction The earliest combination of these three attributes was in Gene Roddenberry's fictional 'Holodecks' in Star Trek, which were inspired by the work of the holographer and inventor of the digital projector, Gene Dologoff." (Bahsoun, Wheatstone, and Challacombe, 2014; p. 20)

At the heart of the facility is a large central space, called the "Sim Deck" (see Figure 2). This is the first simulation center designed around the Sim Deck concept, and the University of Kansas Medical Center in Kansas City has since adopted this layout. It was inspired by the production studios used to support typical medical drama television production in Hollywood. The central idea is to create a space that can be configured to meet any need or any "script." The space is almost 4,000 square feet and is left entirely unconfigured. A three-dimensional, immersive VR construction of the Sim Deck design was utilized and evaluated by the stakeholders prior to construction.

The Sim Deck is supported with abundant access throughout the Sim Deck to electricity, compressed air, and suction. In addition, space above the Sim Deck is two stories in height and houses an overhead catwalk and rigging system, akin to what one might see in a theater. It provides microphones and speakers for audio input and output, lights, and projections systems. Projection backdrops can all be lowered into position and established in any configuration. This was done so that large scale, mass-casualty training could be carried out with suitable environmental cues. In addition, the Sim Deck would meet the need to build specific sets. For example, when the hospital was challenged to undertake site-specific simulation training during the Ebola outbreak of 2015, it was hard to reproduce the exact intensive care unit (ICU) quarantine area. In the new facility, an ICU quarantine set could be built to meet this need.

Physical access to this open stage area needs to be substantial, so that even large structures such as a helicopter shell, a simulated ambulance, or a portion of an airplane fuselage could be installed in the space if a simulation called for it. In addition, it is recognized that when high fidelity simulation is required, the more it engages the five senses the more likely it is for subjects to feel immersed and engaged. This requires control over lighting, sound effects, ancillary special effects, and even smell as part of the stage experience. The support systems for these special effects as well as acoustic systems to impede the spread of sound effects to other areas of the building are also contained in the catwalks and superstructure located on the second floor over the open stage area. 


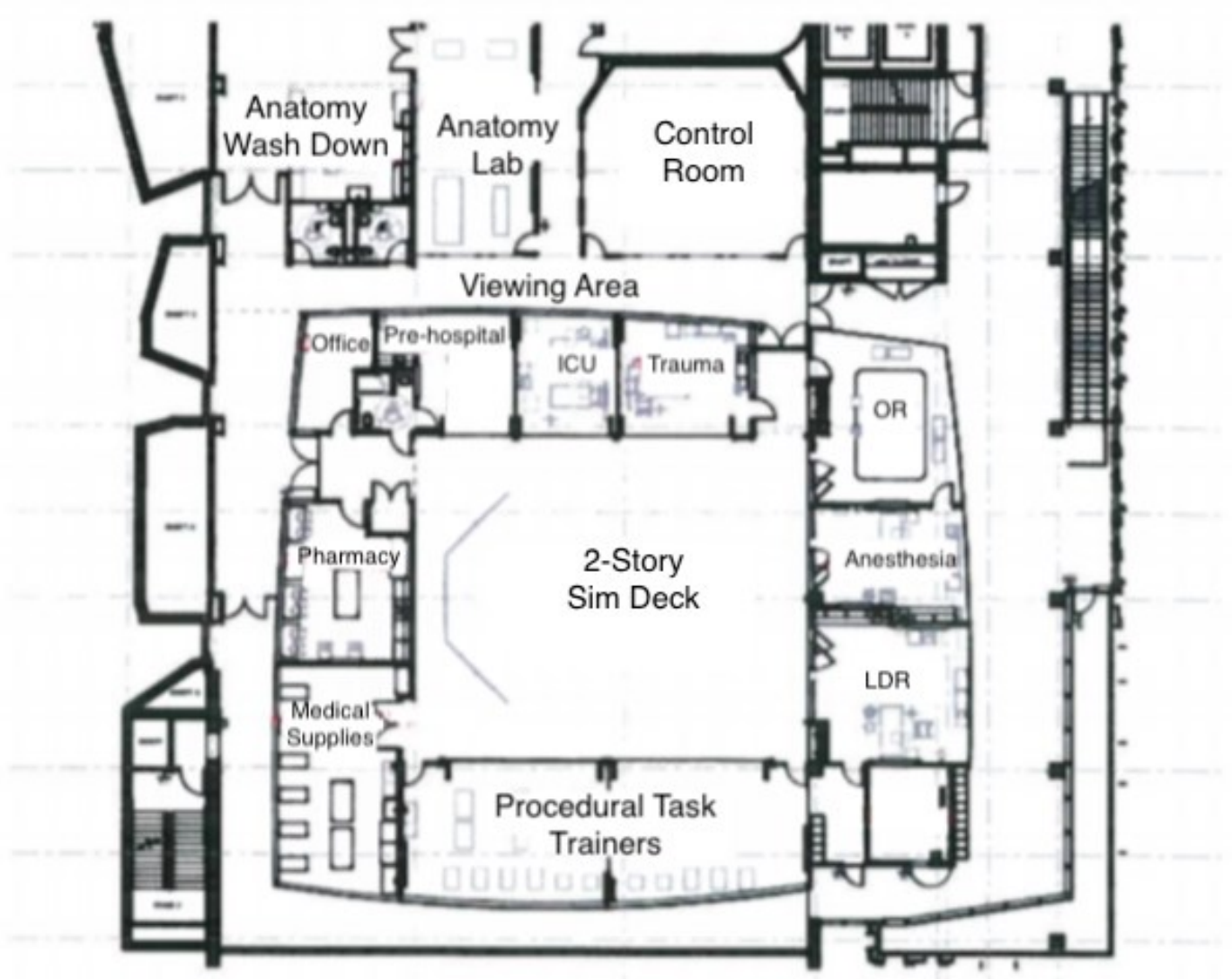

Figure 2: Architect's first drawing of concept of the Sim Deck, surrounded by specialty-specific standing sets and second story above for theatrical superstructure (Courtesy of Co Architects).

Just as important as public access is remote access. All conference rooms, the building amphitheater, debriefing rooms, and simulation suites are all available on the network for digital transmission and reception. All of these areas are also accessible to the ATP's cable network to permit coordination with other simulation facilities in the United States as well coordinating joint, international simulation exercises. In addition, all educational and assessment sessions need to be carefully managed through the use of an advanced learner management system (LMS).

\subsection{Concept of "Stage" versus "Backstage" Areas}

In keeping with our stage or production studio concept, we divided the operational areas of the simulation facility into two broad categories: "front stage areas" and "back stage" areas.

The front stage area is composed of two areas:

(1) The first component of the front stage is composed of public viewing areas that look in on the user areas. A good way to think about it is that these areas are the equivalent to where an audience in a theater can move about or be seated to view what is on stage. These public areas of the simulation facility also include public waiting areas, seating areas, and galleries where ongoing simulation activities can be viewed by the public on large LED screens. Escorted groups of interested lay and scientific groups may also ambulate around the outside of the stage areas in a square-shaped set of galleries/hallways. There are public waiting areas near the main elevator banks that have seating and will also permit individuals to view some training activities carried out in the simulation facility as they occur in real time. If there are no simulation activities 
taking place or the activities are not appropriate for public broadcast (e.g. remedial or proficiency evaluations), then pre-recorded, video loops will be displayed.

(2) The second component of the front stage area is composed of those parts of the simulation facility that would be available to the user populations. User areas are those areas where various user groups can carry out simulation training. These include standing sets or standardized simulation areas like the operating room or ICU. It also includes the larger Sim Deck area.

\subsubsection{Dedicated Simulation Suites: Standing Sets}

In the Stage Area, most rooms are roughly 400 square feet, which is the approximate size of an ample, modern, up-to-date operating room (OR). This size was employed as the standard, modular unit square footage for what we refer to "standing sets;" i.e., these are rooms that are most left in a standardized, predetermined configuration because it is anticipated that regular and frequent use makes it more practical to leave them in a dedicated configuration. However, all of these standing set rooms are suitable to conversion to other uses if the need arose. All rooms are provided with a standardized headwalls (which are also customizable) that include plumbing for hot and cold water and drainage where sinks are designated, abundant electrical power, LED display panels (for patient data and imaging as well as video feeds), compressed gases, suction, power, audiovisual (AV), informational technologies (IT), and telemedicine capabilities providing access to transmit or receive via Arizona Telemedicine Program (ATP) network. Many of the walls incorporated into the standing suites can be retracted to create larger areas for customized uses and configuration.

1. Operating Room (OR): This area is used for surgical training, including aseptic technique procedural training. The OR can employ any infant, pediatric, adolescent, or adult mannequins. The suite includes fully-operational scrub sinks located outside the OR to practice surgical scrubbing, aseptic technique, and patient prep. These rooms also serve as primary rooms for Anesthesia Residency Program training. These rooms have full compressed gas capabilities, suction with state-of-the art gas-scavenging systems and fire suppression systems.

2. Labor \& Delivery (L\&D) Suite: It has approximately the same square footage as the OR, so the L\&D suite could serve as an additional operating room by providing a full OR environment with a high-end L\& D mannequin as well as neonatal intensive care unit (NICU) equipment so that complicated delivery and extraction procedures can be performed.

3. Intensive Care Units (ICU) \#1 -3: These provide ICU facilities for neonatal, adolescent, and adult high-end mannequins. These are all equipped with standard monitors and resuscitation equipment to allow for full-scale, realistic ICU-based scenarios. These three ICU suites are equipped with retractable walls, permitting the suites to be converted to a 4-bed-capacity Emergency Department. One of the ICU rooms is equipped with a patient, disability-accessible OR to provide for training opportunities for patient transfer as well as first-responder training for extraction of victims from bathroom area. The bathroom offers a unique challenge for first responders and nursing staff who much often tend to patients in very cramped quarters.

4. Task Trainer Area: This area is approximately 1600 square feet dedicated for task or procedure trainers. Most task trainers will stay set up in a predetermined configuration but this suite can be customized to any configuration.

5. VR Suite: This area is designated for VR trainers with and without haptic feedback, goggle- or 3Dglasses-based iVR trainers, computer-based single or multi-player gaming or interactive (e.g. avatar-based) learning systems. Individual computer work stations will also be provided.

6. Pharmacy: It is equipped with electronic medication ordering systems, digitally-managed storage of simulated medications, a compounding pharmacy and intravenous solution mixing areas. This suite provides a suitable simulation and assessment area for inter-professional training and the College of Pharmacy.

7. Electronic Medical Records (EMR) and Work Area: This area is a work space of approximately 500 square feet for trainees to access and enter data into EMRs used for support of simulation- 
training needs. EMR-related work products that must be submitted by students can be done through these terminals directly or through a Wi-Fi network.

8. Anatomy Suite: This area contains no human cadavers or parts. Instead, it allows for whole synthetic cadavers made of out of artificial tissues (e.g. biogels) as well as more limited anatomic dissections (e.g. upper extremity). It may be used to demonstrate anatomical landmarks for procedures before proceeding to task trainers in the Task Trainer Area. This suite will also have a 3D-computerized anatomical atlas and immersive, multi-imaging modality stations (such as the Anamotage ${ }^{\circledR}$ Table) which combine anatomical and radiographic data bases.

9. Utility/Storage Room: This nearly 200 square-foot area is for storage of supplies, consumables, and spare parts that should be immediately accessible for running simulations. This room has sinks, wash areas, and drains in the floor so that mannequins and equipment can be cleaned of fluid.

10. De-briefing Rooms: There are two debriefing rooms of approximately 800 square feet. This provides a quieter environment where video can be reviewed and permit more in-depth discussion. Several debriefing conference rooms are included in the simulation facility. They can also be configured for small ( $<20$ individuals), intermediate (20-40 individuals), and large format (50-100 individuals) discussions and debriefings.

11. Command and Control Room: Wireless technology allows for mannequin operation and the recoding and transmitting of video and audio to the debriefing rooms. Multiple simulations and debriefings can be controlled simultaneously from this suite.

Often large pieces of equipment such as hospital beds, an ambulance, and even helicopters may be loaded onto the Sim Deck for large scale simulations.

The floor above the Sim Deck is the COM clinical exam area which provides thirty clinical exam rooms. When needed, these rooms can be configured with task trainers for large scale procedural training and proficiency assessment. It can also be employed for any outpatient or ambulatory-type setting.

\subsubsection{The Back-Stage Area}

This area represents approximately 7,000 square feet that primarily support logistical operations.

1. Offices for administrative and support staff

2. Large storage facilities and consumable supplies

3. Wet and dry workshops for repairs and in-depth overhaul of equipment and mannequins

4. The artificial tissue lab for both soft tissue manufacture and 3-D printing

5. The bio-innovation spaces for carrying out research with bio-industry or government agencies

6. Freight elevators for deliveries of materials and supplies for the stage areas

7. Locker rooms and restrooms for trainees and standardized patients

\subsection{Security \& Access Issues}

One of our missions is to be open to the public and invite members of it to see the lengths to which medical academic institutions and their sister hospitals go to enhance healthcare training and practice. An additional motivation is to encourage low income and economically disadvantaged school children to change their perception that careers in healthcare are out of reach and to engage them at an early age in the medical, biological, and allied sciences. Public access to waiting areas and corridors that look in on the simulation suites will be available during business hours. Access can be controlled through a series of doors which can be closed and only opened by authorized personnel with card-swipe technology. In addition, there may be occasions when selective viewing of simulation suites is required. In such instances, public viewing would add unwanted stress and anxiety. For this reason the glass through which the suite is visible can be selectively opacified with photochromatic glass or screened. 
Back-stage areas are accessible only to individuals provided with security/identity cards. The card swipe system allows extended evening hours and weekend access. Bar code controlled inventory will also ensure equipment and disposables are tracked and accessed only by authorized personnel.

Security is required to ensure that there are adequate medico-legal protections for conducting simulation training. In the simulation environment, this security system creates a barrier between the hospital medication and equipment and simulation medications and equipment to prevent intermingling. Simulation medication is usually inert and the equipment, such as defibrillators, is not maintained to hospital standards.

Access to data entered into the LMS needs to be carefully protected. This is done by maintaining a separate, firewall-protected computer network specific to ASTEC. Access to the LMS also needs to be password protected to ensure that the identity of learners is carefully safeguarded.

\section{CONCLUSIONS AND CHALLENGES}

It is daunting to design a facility for twenty-first century healthcare simulation. It is a shifting landscape with increasing demands, mushrooming support requirements, and expanding missions and outreach. The user groups and stake-holders are becoming increasingly diverse. Commercial developers and researchers are constantly introducing new technologies and new constellations of information technologies to stay abreast of consumer and educational needs. In the final analysis, no design of a simulation facility is fixed. It needs to be built around adaptability and flexibility precisely because there is no good way to predict exactly where health care simulation and technology will carry us. It is important to realize that immersive virtual environments, avatar-based interactivity, and interactive holography will all offer challenges to the architectural notions and designs that have supported large-scale, multi-disciplinary educational facilities dedicated to simulation.

\section{REFERENCES}

Amer. Assoc. Medical Colleges. 2011. "Medical Simulation in Medical Education: Results of an AAMC Survey", https://www.aamc.org/download/259760/data.

Bahsoun, A.N., Wheatstone, S., Challacombe, E. 2014. "Simulation in historical perspective: the history of medical and surgical simulation". Surgical Simulation pp. 20.

Greiner, A.C., Knebel, E. 2003. "Health professions education: a bridge to quality". Institute of Medicine; Washington DC: The National Academic Press.

Hayden, J.K., Smiley, R.A., Alexander, M., et al. July 2014. "The NCSBN national simulation study: a longitudinal, randomized, controlled study of replacing clinical hours with simulation in prelicensure nursing education". J. of Nat. Council of State Boards of Nursing vol 5, pp. S1-S64.

Kelly, L.L. 1979. The Pilot Maker. New York: Grosset \& Dunlap.

Kohn, L.T., Corrigan, J.M., Donaldson, M.S. 2000. "To Err Is Human: Building a Safer Health System". Washington DC: National Academy of Sciences.

Morey, J.C., Simon, R., Jay, G.D., et al. 2002. "Error reduction and performance improvement in the emergency department through formal teamwork training: evaluation results of the MedTeams project". Health Serv. Res. Vol 37, pp. 1553-1581.

Nielsen, P.E., Goldman, M.B., Mann, S., et al. 2007. Effects of teamwork training on adverse outcomes and process of care in labor and delivery: a randomized controlled trial. Obstet. Gynecol., vol 109, pp. 48-55.

Passiment, M., Sacks, H., Huang, G. Medical Simulation in Medical Education: Results of an AAMC Survey. 2011. Washington DC: Association of American Medical Colleges, https:/www.aamc.org/download/259760/data/.

Pronovost, P., Berenholtz, Dorman, T., et al. 2003. "Improving communication in the ICU using daily goals". J. Crit. Care vol 18, pp. 71-75. 
Risser, D.T., Rice, M.M., Salisbury, M.L., et al. 1999. "The potential for improved teamwork to reduce medical errors in the emergency department. The MedTeams Research Consortium". Ann. Emerg. Med. Vol 34, pp. 373-383.

Rosen, K.R. The history of medical simulation. 2008. J. Crit. Care Vol 23, pp. 157-166; http://www.marketsandmarkets.com/PressReleases/healthcare-medical-simulation.asp.

Seropian, M., Lavey, R. 2010. "Design considerations for healthcare simulation facilities". Sim. in Healthcare Vol. 5, pp. 338-345.

Sherwin, J. 2012. "More than make believe: the power and promise of medical simulation". Biomed. Instrumentation \& Technol pp. 254-263.

\section{AUTHOR BIOGRAPHIES}

ALLAN J. HAMILTON, MD, FACS is the Executive Director for the Arizona Simulation Technology and Education Center (ASTEC). He is a Regents' Professor in Neurosurgery the University of Arizona College of Medicine - Tucson. His current research interests include interprofessional education modalities and virtual patient simulation. His email address is allan@surgery.arizona.edu.

MARISSA LOVETT, MS is a second-year medical student enrolled in the College of Medicine, Tucson Campus, University of Arizona College of Medicine and a researcher in ASTEC. She is currently carrying out research on evaluating educational modalities and training in undergraduate medical students. His email address is lovett1@email.arizona.edu.

DAVID BIFFAR, MS is the Director of Operations for the Arizona Simulation Technology and Education Center (ASTEC) and the Center for Advanced Technologies in Healthcare (CATH). He is a Certified Healthcare Simulation Operations Specialist (CHSOS) and an Accreditation Reviewer for the Society for Simulation in Healthcare. His research interests include human factors and usability testing in healthcare environments, interprofessional education modalities, and virtual reality exposure therapy for generalized anxiety disorders. His email address is $\underline{\text { dbiffar@surgery.arizona.edu. }}$

JONATHON KANDA, ASIA is a senior architect working at the firm of Co Architects in Los Angeles, CA that was responsible for the architecture of the Healthcare Simulation and Innovation Building, UAHS, Tucson campus. His email address is jkanda@,coarchitects.com.

JERZY ROZENBLIT, PHD, is a Distinguished Professor in Electrical and Computer Engineering, University of Arizona College of Sciences and Engineering. His current research interests include the use of virtual reality and augmented reality in robotic surgical design. His email address is jr@ece.arizona.edu.

RONALD WEINSTEIN, MD is a Professor of Pathology and the Director of the Arizona Telemedicine Program. His current research interests are evaluating the necessity of present, on-site simulation facilitators versus tele-esimulation with remote simulation facilitators. His email address is rweinstein@telemedicine.arizona.edu. 